\title{
Optimization of Pectin Extractions from Walnut Green Husks and Characterization of the Extraction Physicochemical and Rheological Properties
}

\author{
Marjan Nouri*1 ${ }^{1}$, Mohsen Mokhtarian ${ }^{1}$ \\ 1- Assistant Professor, Department of Food Science and Technology, Roudehen Branch, Islamic Azad University, Roudehen, Iran
}

\section{A B S T R A C T}

Background and Objectives: Walnut is a nutrient with green husks containing pectin. Extraction of this pectin is valuable due to economic and environmental aspects.

Materials and Methods: Effects of three variables of $\mathrm{pH}$ values (1, 1.5 and 2), extraction temperatures (60, 70 and $80^{\circ} \mathrm{C}$ ) and process times (60, 90 and $120 \mathrm{~min}$ ) were assessed on extraction efficiency rate, esterification degree and galacturonic acid of pectin extracted from walnut wastes using response surface statistical method. Furthermore, total ash, MW, emulsifier, rheological and Fourier transform infrared spectroscopy assessments were carried out on optimum samples.

Results: Based on the results, optimum conditions for pectin extraction from walnut green husks with the highest extraction efficiency rate $(25.76 \%)$, esterification degree $(54.28 \%)$ and galacturonic acid $(64.49 \%)$ were associated to $\mathrm{pH}$ 1.75 , process temperature of $80{ }^{\circ} \mathrm{C}$ and extraction time of $120 \mathrm{~min}$. The most emulsion stability of the walnut waste of pectin was seen at $4{ }^{\circ} \mathrm{C}$ and on the first day of storage. Under optimal extraction conditions, MW of the walnut green husks was $38.88 \mathrm{kD}$. Optimum sample solution of the extracted pectin exhibited viscous and pseudoplastic behaviors.

Conclusions: Fourier transform infrared spectroscopy spectral diagrams of the optimal pectin samples have shown presence of galacturonic acid; thus, walnut wastes can be used as a rich source of pectin.

Keywords: Walnut green husk, Pectin, Esterification degree, Galacturonic acid

\section{Introduction}

Iran is well ranked for low price and good quality of its agricultural products. Favorable weather conditions contribute to quality and taste of these products (1). The average annual agricultural wastes are estimated as 35\%. To decrease these wastes, methods such as appropriate harvesting, hygienic transportation, disinfection, packaging and optimal use of husks and leaves of the agricultural products can help (2). Walnut wastes include green husks, outer and inner wood husks and thin inner husks. The walnut green husk or pericarp is a byproduct and useful source of phytochemical compounds similar to those of walnut leaves, which increases values of walnut productions (3). The walnut green husk is a good source of fatty acids, citric and malic organic acids, phytosterol sugar emulsions, chlorophylls, joglones, polysaccharides such as pectin, vitamins and various minerals, including potassium (0.95\%), nitrogen $(0.84 \%)$, phosphorus $(0.78 \%)$, calcium $(0.49 \%)$ and magnesium $(0.10 \%)$ (4). Hydrocolloid pectin includes a complex family of polysaccharides present in plant cell walls and is one of the most important biopolymers present in plant species $(5,6)$. The maximum quantity of pectin is found in premature fruits. During ripening, pectin is degraded by pectin esterase and pectinase enzymes, the middle lamella breaks and cells are separated from each other by decreasing the percentage of pectin and hence fruits gradually soften. Chemical compound, structure and percentage of pectin vary in various plants (7).

Pectin is widely used in food industries as colloidal additive with gel properties, immobilizer, condenser and emulsifier. Traditional use of pectin in marmalades, jams and fruit jellies is common, 
decreasing aquatic activity as well as creating favorable tissues (8). Pectin is extracted from pulp and agricultural product wastes such as peach (9), sugar beet (10), orange peel, sunflower oilseed (11), apple, lemon sour, banana peel (12), citrus peel, husk of blackberry tree branch (13), grapefruit peel (14), Akebia trifoliata husk (15), peanut and sugar beet roots (16), cocoa bean husk, grape pulp (17), golden kiwi, orange peel (18), tomato, carrot (19), pistachio green husk (20) and eggplant peel and cap. In recent years, recycling valuable compounds, controlling importing costs of these compounds and decreasing wastes have been great concerns discussed in country waste reduction panels. Use of walnut green husk wastes not only decrease environmental pollutions, but also includes the valuable pectin with special properties in food industries. To the best of the authors' best knowledge, no studies have been carried out on the extraction of pectin from walnut wastes. Therefore, the major aims of the present study were optimization of pectin extractions from walnut green husks and characterization of the extraction physicochemical and rheological properties.

\section{Materials and Methods}

\section{Extraction and separation of pectin from walnut green husks}

Fresh green walnuts were purchased from a local market in Tehran, Iran, and their green husks were separated and thoroughly washed with water. After drying, walnuts were cut into small pieces and dried in oven at $60{ }^{\circ} \mathrm{C}$ for $48 \mathrm{~h}$ to reach a constant weight and then flour-shaped granules were formed using mill. Powder was stored in cool and dry conditions ($18{ }^{\circ} \mathrm{C}$ ) using capped containers. Pectin extraction process was carried out based on a method by Chaharbagh et al. (2017) with modifications. In this method, various extraction conditions such as $\mathrm{pH}$ $\left(\mathrm{X}_{1}\right)$, temperature $\left(\mathrm{X}_{2}\right)$ and process time $\left(\mathrm{X}_{3}\right)$ were set up to achieve optimal conditions for pectin extraction. Briefly, $10 \mathrm{~g}$ of the powder from the previous step were mixed with $200 \mathrm{ml}$ of desired solvent such as acidified distilled water with citric acid at various $\mathrm{pH}$ of $1,1.5$ and 2 . Heating process and stirring were carried out using water bath at various temperatures of 60,70 and $80^{\circ} \mathrm{C}$ and extraction times of 60,90 and $120 \mathrm{~min}$ for both parts of the walnut wastes separately (Table 1). Range of the experiments for each agent was selected based on the results from previous studies and the initial experiments from the present study.

Table 1. Various factors affecting extraction of pectin from the walnut green husks

\begin{tabular}{llllll}
\hline Factor & Unit & Code & \multicolumn{2}{l}{ Surface } \\
\hline & & & -1 & 0 & 1 \\
$\mathrm{pH}$ & & $\mathrm{X}_{1}$ & 1 & 1.5 & 2 \\
Process temperature & Celsius degree & $\mathrm{X}_{2}$ & 60 & 70 & 80 \\
Process time & Minute & $\mathrm{X}_{3}$ & 60 & 90 & 120 \\
\hline
\end{tabular}

After cooling samples at ambient temperature, the pulp was separated from the solution accurately using mesh and centrifuge (4000 rpm, $20 \mathrm{~min})$. Then, supernatant liquid was passed through filter papers and stored at refrigerator temperature $\left(4{ }^{\circ} \mathrm{C}\right)$. To extract pectin and precipitate it in the isolated liquid phase, ethanol (96\%) was added at a ratio of 1:2 until extracted pectin formed aggregation. Samples were stored at refrigerator temperature for $10 \mathrm{~h}$ to completely precipitate the pectin. To increase purity of the residual precipitate, several times washing with ethanol and methanol, centrifuging and filtering through filter papers were carried out. Then, oven was used to dry pectin samples at $55{ }^{\circ} \mathrm{C}$ for $24 \mathrm{~h}$. After weighing, samples were powdered using shredder and laboratory mesh No. 60 and then stored in closed containers in cool and dry conditions.

\section{Extraction efficiency rate}

Efficiency rate of the pectin extraction from various treatments was assessed using Equation 1 (13).

\section{Equation 1.}

Extracted pectin efficiency rate $(\%)=$ pure pectin weight $(\mathrm{g}) /$ initial dry powder weight $(\mathrm{g}) \times 100$

\section{Esterification degrees}

In the present study, esterification degrees were assessed using potentiometric titration method. In this method, $0.1 \mathrm{~g}$ of dry pectin was first mixed with $3 \mathrm{ml}$ of $96 \%$ ethanol. Then, $20 \mathrm{ml}$ of deionized distilled water (D.W.) were added to the mixture at $40{ }^{\circ} \mathrm{C}$ and stirred using heater equipped with a magnetic stirrer until the pectin was completely dissolved. Three drops of phenolphthalein were added to the mixture and titrated with $0.1 \mathrm{M}$ sodium hydroxide until a palepink appeared (initial volume). Then, $10 \mathrm{~mL}$ of $0.1 \mathrm{M}$ sodium hydroxide were added to the neutralized solution and stirred for $30 \mathrm{~min}$ using magnetic stirrer until pectin was saponified. Then, $10 \mathrm{ml}$ of $0.1 \mathrm{M}$ hydrochloric acid were added to the mixture and stirred until the pink color was completely eliminated, 
the residual hydrochloric acid was titrated with $0.1 \mathrm{M}$ sodium hydroxide until a pink color appeared (secondary volume). At the end of the process, the esterification degree was calculated based on the Equation 2 (21).

\section{Equation 2.}

Esterification degree $(\%)=$ secondary volume / secondary volume + initial volume $\times 100$

\section{Galacturonic acid content}

The galactoronic acid content was assessed based on a method by Nateghi et al. (2017). Briefly, colorimetric method was carried out using metahydroxydiphenyl reagent. Furthermore, solutions were prepared and galacturonic acid calibration curve was plotted.

\section{Quantity of ash}

Total ash of the samples was assessed based on the AOAC standard methods using furnace system with standard No. 942/05. (23).

\section{Molecular weight (MW) calculation}

To assess parameters needed to calculate intrinsic viscosity of the pectin solutions, capillary glass viscometer at constant temperature and Mark Houwinke equation were used. The intrinsic viscosity was calculated by drawing diagrams of reduced viscosity numbers (vertical axis) versus concentrations (horizontal axis) and extrapolating them to zero concentration (Weska et al., 2007). Then using Equations 3-6, MW of the optimal samples was calculated.

Equation 3. $\rho / \eta=v$

Equation 4. $\eta_{\mathrm{Sp}}=\left(\eta_{\text {solution }}-\eta_{\text {solvent }}\right) / \eta_{\text {solvent }}$

Equation 5. $\eta_{\mathrm{Sp} / \mathrm{C}}=[\eta]+\mathrm{K}[\eta]^{2} \times \mathrm{C}$

Equation 6. $[\eta]=\mathrm{KM}^{\alpha}{ }_{\mathrm{w}}$

Where, $v$ was cinematic viscosity (stoke), $\eta$ was dynamic viscosity (poise), $\rho$ was soluble density $(\mathrm{g} / \mathrm{ml}), \eta_{\mathrm{sp}}$ was specific viscosity, $\eta_{\mathrm{sp}} / \mathrm{C}$ was reduced viscosity $\left(\mathrm{ml} \mathrm{g}^{-1}\right), \mathrm{C}$ was soluble concentration $\left(\mathrm{g} \mathrm{ml}^{-}\right.$ ${ }^{1}$ ), $\mathrm{K}$ was correction coefficient (constant number for each polymer, $\left.\mathrm{g} \mathrm{ml}^{-1}\right),[\eta]$ was intrinsic viscosity $(\mathrm{ml}$ $\left.\mathrm{g}^{-1}\right), \mathrm{M}_{\mathrm{w}}$ was MW and $\alpha$ was correction coefficient (constant number for each polymer solution system).

\section{Rheological properties}

Of the extracted pectin samples at the optimum point, a solution with $1 \%$ concentration was prepared and stirred for approximately $9 \mathrm{~h}$ using magnetic stirrer. Dynamic rheology test was carried out at a constant temperature of $25^{\circ} \mathrm{C}$ using rotary rheometer (Physica MCR 300, Germany). In this method, the strain scanning test $(0.01-100 \%$ at $1 \mathrm{~Hz})$ was carried out first to calculate the linear viscoelastic range. The storage modulus $\left(\mathrm{G}^{\prime}\right)$ and dissipation $\left(\mathrm{G}^{\prime \prime}\right)$ were assessed using oscillation test with low oscillation amplitude at frequencies of $0.1-100 \mathrm{~Hz}$ at $1 \%$ strain (25).

\section{Emulsifier property}

To assess the emulsifier activity and emulsion stability, Nateghi et al. (2017) method was used with modifications. In this method, the emulsion was prepared by adding $5 \mathrm{ml}$ of sunflower oil to $5 \mathrm{ml}$ of the pectin solution $(5 \% \mathrm{v} / \mathrm{w})$ and $0.02 \%$ sodium azide was used to inhibit bacterial growth. Selected sample was mixed at $10,000 \mathrm{rpm}$ for $4 \mathrm{~min}$ using homogenizer. The new emulsion prepared at 4000 $\mathrm{rpm} \mathrm{min}^{-1}$ was centrifuged at room temperature for 5 $\min$. At the end of the process, the emulsifier activity was calculated using Equation 7.

Equation 7.

Emulsifier activity $(\%)=$ volume of the emulsified layer $/$ total volume of the sample $\times 100$

To investigate stability properties of the emulsion, prepared sample was stored at 23 and $4{ }^{\circ} \mathrm{C}$ for 1 and $30 \mathrm{~d}$, then the property was calculated based on the Equation 8.

Equation 8.

Emulsion stability $(\%)=$ volume of the remaining emulsion layer / volume of the initial emulsion $\times 100$

\section{Fourier transform infrared spectroscopy (FTIR) spectroscopy property}

To prepare solid samples for use in FTIR spectrometer (Vector 22), dry and fully powdered sample was compressed with potassium bromide in a glass tube and then inserted into the spectrometer and a desired spectrum in the range $\left(400-4000 \mathrm{~cm}^{-1}\right)$ was reported (21).

\section{Statistical method}

First, data were tested for normality and if were normal, analysis of variance was used. Pectin samples extracted under various extraction conditions using response surface methodology in form of box benkan design, 15 treatments were assigned to the initial material (Equation 9). Each treatment was carried out in two replications (30 samples). In the next step, 
sequence of dependent variables (total ash, MW, emulsifier and rheological) to independent variable changes of the pectin extraction from walnut green husks was investigated using Equation 9.

Equation 9.

$\mathrm{Y}=\beta_{0}+\sum_{i=1}^{3} \beta_{i} X_{i}+\sum_{i=1}^{3} \beta_{i i} X_{i}^{2}+\sum_{i=1}^{3} \sum_{j<i} \beta_{i j} X_{i} X_{j}$

In this study, Minitab 16, Design Expert 7 and MS Excel were used for the statistical analysis.

\section{Results}

\section{Optimization of the pectin extraction efficiency rate}

Schematic matrix and experimental and predicted results of pectin extraction efficiency rate for each trial unit are presented in Table 2. These results showed that the pectin extraction efficiency rate in walnut green husks ranged $13.01-26.02 \%$.

Table results of variance efficiency analysis, esterification degree and galacturonic acid proportion showed that lack-of-fit (non-processing test) at 0.05 was not significant and laboratory data were in good conditions based on the model. Furthermore, calculation of $r$-sq (adj) $R^{2}$ and $R^{2}$ indicated that the model was in a satisfactory condition. In Table $3, p$ values showed importance of the equation coefficients, which showed that linear and quadratic effects of all independent variables were significant (Table 3). After converting results of the t-test table to equation form, all sentences with no statistical significance were removed and equations were transformed to 10,11 and 12 , respectively.

Equation 10. $\mathrm{Y}_{1}=0.16+3.73 \mathrm{X}_{2}+2.53 \mathrm{X}_{3}-\mathrm{X}_{1}^{2}-0.65 \mathrm{X}_{2}^{2}$ $+0.52 \mathrm{X}_{1} \mathrm{X}_{3}+1.20 \mathrm{X}_{2} \mathrm{X}_{3}$

Equation 11. $\mathrm{Y}_{2}=58.69+1.80 \mathrm{X}_{1}+2.46 \mathrm{X}_{1}^{2}-2.80 \mathrm{X}_{2}^{2}-$ $3.02 \mathrm{X}_{3}^{2}+1.11 \mathrm{X}_{1} \mathrm{X}_{2}-1.21 \mathrm{X}_{2} \mathrm{X}_{3}$

Equation 12. $\mathrm{Y}_{3}=68.32+1.15 \mathrm{X}_{2}-3.01 \mathrm{X}_{1}^{2}-1.94 \mathrm{X}_{2}^{2}-$ $1.12 \mathrm{X}_{1} \mathrm{X}_{2}$

Where, $Y_{1}, Y_{2}$ and $Y_{3}$ were the efficiency rate, esterification degree and pectin galacturonic acid proportion of the green husks, respectively. Moreover, Independent Variables $\mathrm{X}_{1}, \mathrm{X}_{2}$ and $\mathrm{X}_{3}$ were responses of the coded levels.

Effects of various levels of variables on the quantity of walnut husk wastes can be shown using Equation 10 (Table 3) (Figures 1a, b). Figure 1a shows effects of increasing $\mathrm{pH}$ and process time on extracted pectin efficiency rate at constant temperature and central point $\left(\mathrm{X}_{2}, 70{ }^{\circ} \mathrm{C}\right)$. By increasing $\mathrm{pH}$, quantity of the extracted pectin increased to a certain point. Then, process was reversed and declined. Based on the model equation, it can be concluded that the pectin efficiency rate increased and then decreased when $\mathrm{pH}$ increased from 1 to 2 .

Table 2. Test design based on the models using results of optimal extraction conditions on efficiency rate, esterification degree percentage and galacturonic acid of the pectin from walnut green husks (mean \pm standard error)

\begin{tabular}{|c|c|c|c|c|c|c|c|c|c|}
\hline \multicolumn{2}{|c|}{$\begin{array}{c}\text { Galacturonic acid proportion } \\
(\%)\end{array}$} & \multicolumn{2}{|c|}{ Esterification degree $(\%)$} & \multicolumn{2}{|c|}{ Efficiency rate $(\%)$} & \multirow{2}{*}{$\begin{array}{c}\begin{array}{c}\text { Walnut } \\
\text { green husk }\end{array} \\
\text { Treatment }\end{array}$} & \multicolumn{3}{|c|}{ Code } \\
\hline (Predicted) & (Real) & (Predicted) & (Real) & (Predicted) & (Real) & & $\mathrm{X}_{1}$ & $\mathrm{X}_{2}$ & $\mathrm{X}_{3}$ \\
\hline 61.36 & $61.75 \pm 0.02$ & 57.246 & $56.74 \pm 1.05$ & 13.13 & $13.12 \pm 0.02$ & 1 & -1 & -1 & -1 \\
\hline 63.02 & $62.31 \pm 0.07$ & 58.639 & $58.50 \pm 2.01$ & 13.85 & $14.03 \pm 0.09$ & 2 & 1 & -1 & 1 \\
\hline 65.92 & $66.64 \pm 0.10$ & 55.861 & $56.00 \pm 1.07$ & 21.01 & $20.84 \pm 0.02$ & 3 & -1 & 1 & -1 \\
\hline 63.09 & $62.71 \pm 0.03$ & 61.694 & $62.20 \pm 0.70$ & 20.92 & $20.94 \pm 0.10$ & 4 & 1 & 1 & 1 \\
\hline 64.39 & $64.12 \pm 0.05$ & 55.505 & $55.92 \pm 3.02$ & 15.79 & $16.05 \pm 0.05$ & 5 & -1 & 0 & -1 \\
\hline 63.26 & $64.09 \pm 0.03$ & 60.153 & $60.20 \pm 1.02$ & 15.05 & $15.12 \pm 0.01$ & 6 & 1 & 0 & 1 \\
\hline 64.75 & $63.93 \pm 0.02$ & 57.168 & $57.12 \pm 0.07$ & 19.80 & $19.74 \pm 0.06$ & 7 & -1 & 0 & -1 \\
\hline 64.70 & $64.98 \pm 0.01$ & 59.745 & $59.33 \pm 1.08$ & 21.17 & $20.92 \pm 0.02$ & 8 & 1 & 0 & 1 \\
\hline 63.11 & $63.00 \pm 0.05$ & 50.929 & $51.02 \pm 0.70$ & 13.24 & $13.01 \pm 0.01$ & 9 & 0 & -1 & 0 \\
\hline 66.68 & $66.24 \pm 0.01$ & 54.194 & $53.64 \pm 1.05$ & 18.30 & $18.22 \pm 0.08$ & 10 & 0 & 1 & 0 \\
\hline 65.26 & $65.71 \pm 0.03$ & 53.986 & $54.54 \pm 1.62$ & 15.89 & $15.98 \pm 0.06$ & 11 & 0 & -1 & 0 \\
\hline 66.33 & $66.45 \pm 0.07$ & 52.391 & $52.30 \pm 0.09$ & 25.78 & $26.02 \pm 0.07$ & 12 & 0 & 1 & 0 \\
\hline 68.32 & $68.23 \pm 0.05$ & 58.693 & $58.88 \pm 0.60$ & 18.89 & $18.64 \pm 0.01$ & 13 & 0 & 0 & 0 \\
\hline 68.32 & $68.01 \pm 0.04$ & 58.693 & $58.65 \pm 0.90$ & 18.89 & $19.00 \pm 0.05$ & 14 & 0 & 0 & 0 \\
\hline 68.32 & $68.72 \pm 0.03$ & 58.693 & $58.55 \pm 1.00$ & 18.89 & $19.05 \pm 0.04$ & 15 & 0 & 0 & 0 \\
\hline
\end{tabular}


Table 3. Analysis of variance from the quadratic model for efficiency rate, esterification degree and percentage of the galacturonic acid pectin

$\begin{array}{lll}\text { Galacturonic acid proportion }(\%) & \text { Esterification degree }(\%) & \text { Efficiency rate (\%) }\end{array}$

\begin{tabular}{|c|c|c|c|c|c|c|c|c|c|}
\hline $\mathrm{P}$ number & F number & $\begin{array}{c}\text { Mean } \\
\text { squared }\end{array}$ & P number & F number & $\begin{array}{c}\text { Mean } \\
\text { squared }\end{array}$ & P number & F number & $\begin{array}{c}\text { Mean } \\
\text { squared }\end{array}$ & $\begin{array}{l}\text { Walnut green } \\
\text { husk waste }\end{array}$ \\
\hline$<0.009^{\mathrm{a}}$ & 10.50 & 7.35 & $<0.000^{\mathrm{a}}$ & 45.27 & 14.3709 & $<0.000^{\mathrm{a}}$ & 229.14 & 19.48 & \\
\hline 0.367 & 0.99 & 0.69 & 0 & 82.22 & 26.1003 & 0.187 & 2.33 & 0.19 & $\mathrm{X}_{1}$ \\
\hline 0.011 & 15.33 & 10.74 & 0.09 & 4.39 & 1.3945 & 0.000 & 1312.60 & 111.60 & $\mathrm{X}_{2}$ \\
\hline 0.187 & 2.34 & 1.63 & 0.176 & 2.48 & 0.7875 & 0.000 & 603.46 & 51.30 & $X_{3}$ \\
\hline 0.001 & 48.02 & 33.64 & 0 & 70.79 & 22.4732 & 0.001 & 44.02 & 3.75 & $\mathrm{X}_{1}^{2}$ \\
\hline 0.007 & 20.01 & 14.02 & 0 & 91.22 & 28.9563 & 0.007 & 18.75 & 1.59 & $\mathrm{X}_{2}^{2}$ \\
\hline 0.066 & 5.50 & 3.85 & 0 & 105.93 & 33.6289 & 0.673 & 0.20 & 0.01 & $\mathrm{X}_{3}^{2}$ \\
\hline 0.044 & 7.19 & 5.04 & 0.011 & 15.53 & 4.9284 & 0.224 & 1.93 & 0.16 & $X_{1} X_{2}$ \\
\hline 0.547 & 0.42 & 0.29 & 0.126 & 3.37 & 1.0712 & 0.015 & 13.09 & 1.11 & $X_{1} X_{3}$ \\
\hline \multirow[t]{3}{*}{0.196} & 2.23 & 1.35 & 0.008 & 18.6 & 5.9049 & 0.000 & 68.60 & 5.83 & $\mathrm{X}_{2} \mathrm{X}_{3}$ \\
\hline & & 0.70 & & & 0.3174 & & & 0.08 & Error remaining \\
\hline & & 0.13 & & & 0.0286 & & & 0.05 & Pure error \\
\hline $0.111^{\mathrm{b}}$ & 8.17 & 1.07 & $0.054^{\mathrm{b}}$ & 17.81 & 0.51 & $0.331^{\mathrm{b}}$ & 8.17 & 0.10 & R-sq (adj) \\
\hline Justified $\mathrm{R}^{2}$ & Predicted $R^{2}$ & $\mathrm{R}^{2}$ & Justified $\mathrm{R}^{2}$ & Predicted $\mathrm{R}^{2}$ & $\mathrm{R}^{2}$ & Justified $\mathrm{R}^{2}$ & Predicted $\mathrm{R}^{2}$ & $\mathrm{R}^{2}$ & \\
\hline $85.93 \%$ & $84.8 \%$ & $94.97 \%$ & $96.61 \%$ & $81.2 \%$ & $98.79 \%$ & $85.93 \%$ & $84.80 \%$ & $94.97 \%$ & \\
\hline
\end{tabular}
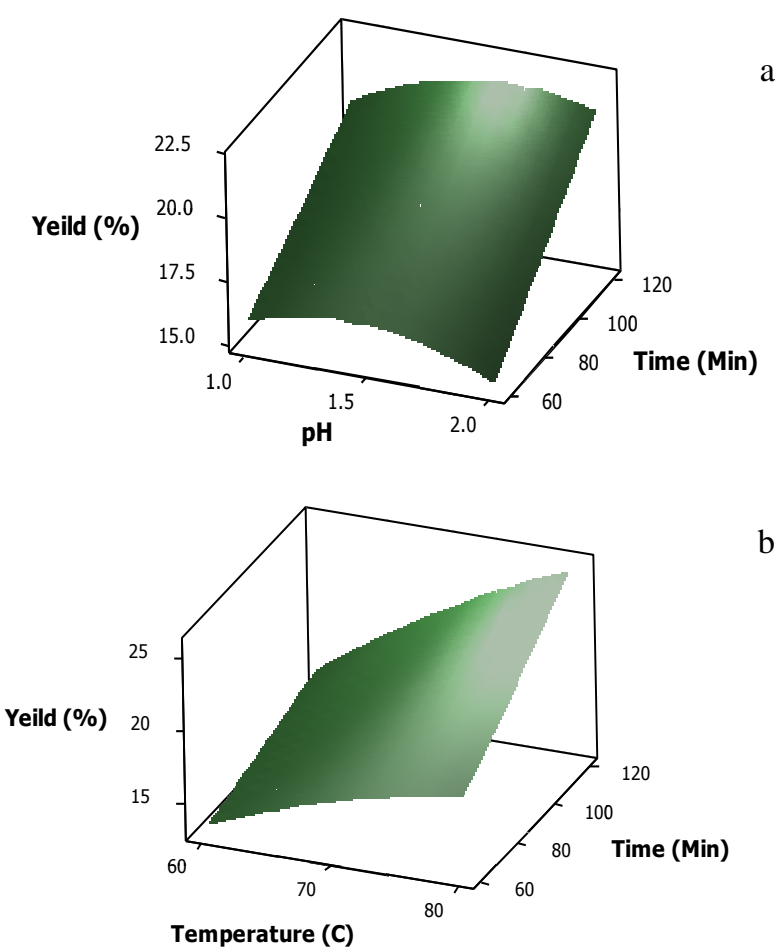

Figure 1. Three-dimensional diagrams of the response surface based on the independent factor changes in walnut husk pectin efficiency rate

The optimum values of each extraction variable were calculated using the equation as the highest efficiency rate of walnut green husks was $25.84 \%$ at $\mathrm{pH} 1.62,80^{\circ} \mathrm{C}$ and $120 \mathrm{~min}$.

\section{Optimization of pectin esterification degree}

This factor represents the number of moles of methanol per 100 moles of galacturonic acid. The pectin esterification degree is one of the key factors in describing properties of the pectin gels. Solubility of pectin in water and its gelation strength depend on the pectin esterification degree (21). Based on Table 2, esterification proportion of the samples from walnut green husks ranged $52.30-60.20 \%$. Effects of various levels of variables on pectin esterification degree can be described using Equation 11 (Table 3) (Figure 2a, b). Figure $2 \mathrm{a}$ shows effects of increasing temperature and time on esterification degree of the extracted pectin under conditions; in which, $\mathrm{pH}$ was constant at the central point $\left(\mathrm{X}_{1}, 1.5\right)$. By increasing these two target factors, esterification degree of the extracted pectin increased to a certain point and then decreased. Figure $2 \mathrm{~b}$ shows effects of the temperature and $\mathrm{pH}$ changes on pectin esterification degrees with time constant at the central point $\left(\mathrm{X}_{3}, 90 \mathrm{~min}\right)$. This shows that $\mathrm{pH}$ increased with increased esterification degrees, but this increase was seen with increases in temperature. Based on the model equation, pectin esterification degree increased when $\mathrm{pH}$ increased from 1 to 2 . However, increased process temperature and time initially increased the esterification degree and then decreased it. Rate of the pectin extraction increased with increased temperature and time. However, the lowest pectin esterification degree was 
achieved at the optimum points of the extraction temperature and time. The optimum values of each extraction variable were achieved using equation; where, the highest pectin esterification degree was achieved from walnut green husks (63.19\%) linked to $\mathrm{pH} 2$, process temperature of $72.92{ }^{\circ} \mathrm{C}$ and extraction time of $87.27 \mathrm{~min}$.
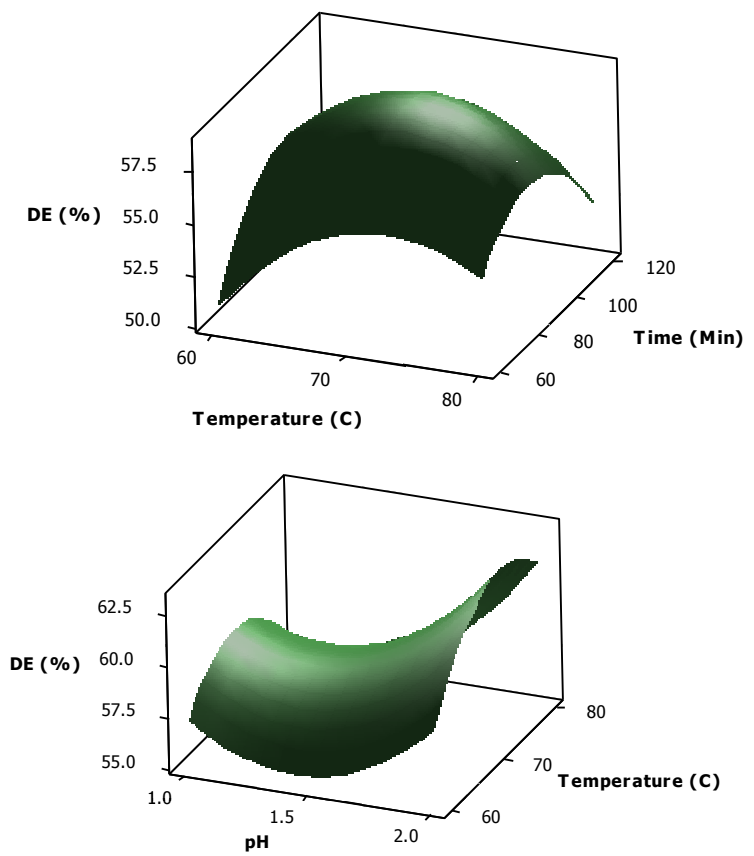

b

Figure 2. Three-dimensional diagrams of the response surface corresponding to changes of the independent factors in degree of walnut husk pectin esterification

\section{Optimization of galacturonic acid proportion}

Since galacturonic acid is a major constituent of pectin. Quantitation of galacturonic acid demonstrates purity of the extracted pectin, which is important for biological studies and pharmaceutical and nutritional applications. Concentration of galacturonic acid varies in various plants (19). Effects of various variables on galacturonic acid pectin can be demonstrated using Equation 12 (Table 3, Figure 3). Figure 3 shows effects of increasing process temperature and $\mathrm{pH}$ on proportion of the extracted galacturonic acid pectin under conditions; where, the time was constant at the central point $\left(\mathrm{X}_{1}, 90 \mathrm{~min}\right)$. By increasing these two target factors, proportion of the extracted galacturonic acid pectin increased to a certain point and then decreased. Esterification rate of the samples achieved from walnut green husks ranged 61.75-68.72 (Table 2). Proportion of the galacturonic acid pectin increased when $\mathrm{pH}$ increased from 1 to 1.44. However, the factor decreased with increased
pH. Furthermore, increased temperature increased and then decreased the galacturonic acid proportion. The optimum values for the highest proportion of galacturonic acid pectin from walnut green husks $(68.53 \%)$ included $\mathrm{pH} 1.44$, process temperature of $72.92{ }^{\circ} \mathrm{C}$ and extraction time of $93.33 \mathrm{~min}$.

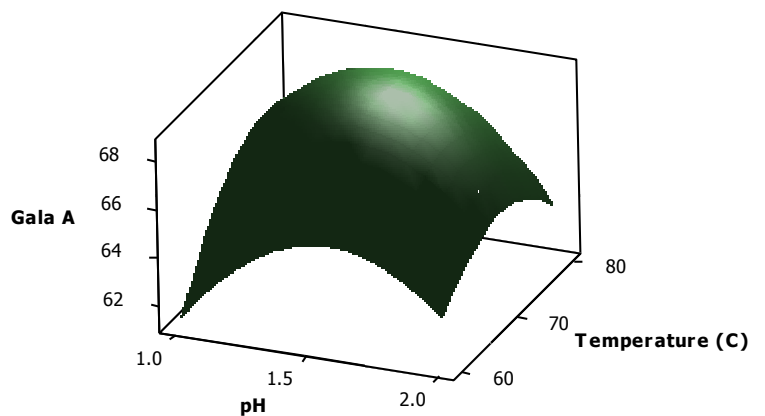

Figure 3. Three-dimensional response surface diagram of the independent factor changes in galacturonic acid proportion of the walnut husk pectin

\section{Optimization conditions of the pectin from walnut green husks}

Figure 4 shows the optimum diagrams of the efficiency rate, esterification degree and galacturonic proportion of pectin extracted from walnut green husks. It can be seen that the optimum conditions for pectin extraction from walnut green husks with the highest efficiency rate (25.76), esterification degree (54.28) and galacturonic acid proportion (64.94) linked to $\mathrm{pH} 1.75$, process temperature of $80{ }^{\circ} \mathrm{C}$ and extraction time of $120 \mathrm{~min}$.

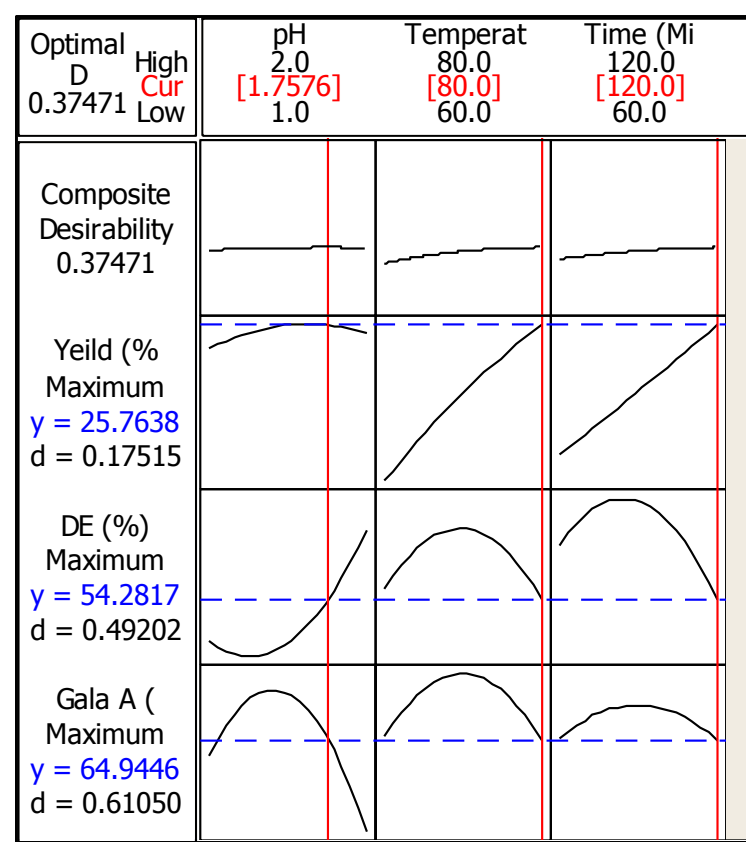

Figure 4. Optimization diagram of the pectin extraction conditions based on the efficiency rate, esterification degree and galacturonic percentage of the pectin samples extracted from walnut green husks 


\section{Quantity of the ash}

Ash is one of the most important factors in gel strength. Studies have shown that high ash contents result in formation of the junction and gel network; therefore, pectin with less ash contents is able to form further gels (26). Effects of ash are usually found in low-ester pectins because further carboxyl groups are available to react with the ash. In the present study, this test was carried out since the extracted pectin included low ester contents. Results showed that ash contents of the pectin powder included $1.05 \%$.

\section{Molecular weight calculation}

The intrinsic viscosity value of a polymer is a measure of the hydrodynamic volume of polymer molecules and shows the molecular capacity of polymers to increased viscosity. Intrinsic viscosity is affected by MW, esterification degree, temperature and solution concentration and $\mathrm{pH}$. The average MW of pectin is a key parameter in gel formation by pectin (27). In this study, intrinsic viscosity of the extracted pectin from walnut husks included $1.38\left(\mathrm{mg} \mathrm{g}^{-1}\right)$ at optimum conditions, with $\mathrm{K}$ and $\alpha$ values of $9.55 \times$ $10^{-2}$ and 0.73 from previous studies, including raji et al. (2017) study. The MW of pectin was calculated using Equation 13.

Equation 13. $\eta=9.55 \times 10^{-2}(\mathrm{MW})^{0.73}$

In this study, MW of the extracted pectin samples at optimum conditions included $38.88 \mathrm{kDa}$.

\section{Rheological properties}

Gels are viscoelastic materials and hence dynamic rheological tests are useful for the assessment of gel properties and its gelation process.

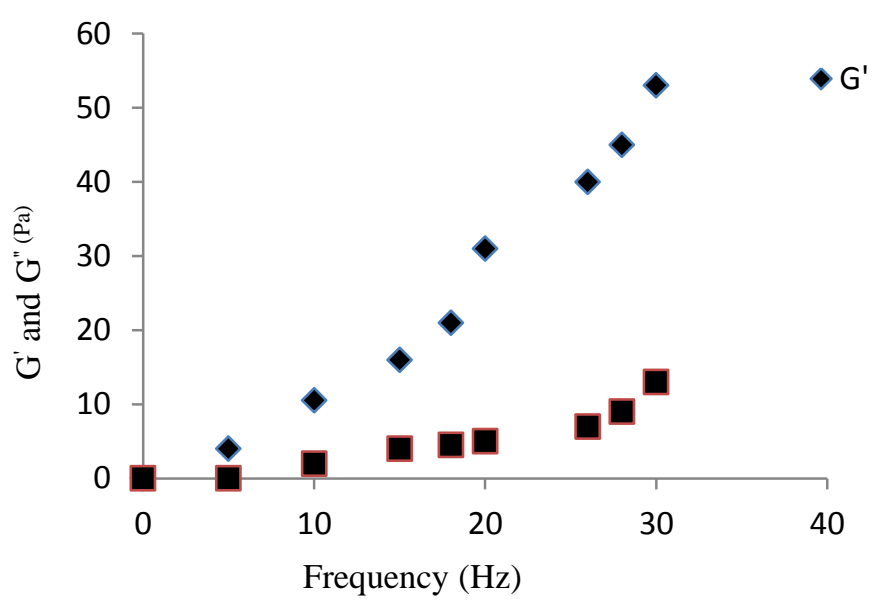

Figure 5. Variation diagram of the elastic $\left(G^{\prime}\right)$ and viscose $\left(\mathrm{G}^{\prime \prime}\right)$ coefficients for the optimal samples of walnut husk pectin at $1 \%$ concentrations

Figure 5 shows variation diagram of $\mathrm{G}^{\prime}$ and $\mathrm{G}^{\prime \prime}$ modulus for the optimal pectin sample at $1 \%$ concentrations. The near-gel optimum behavioral pectin sample showed that the elastic coefficient $\left(\mathrm{G}^{\prime}\right)$ was larger than the reserve $\left(G^{\prime \prime}\right)$ coefficient at all frequency amplitudes, indicating a pseudo-solid behavior similar to that of elastic network (28).

\section{Emulsifier properties}

Pectin increases the stability of emulsions by increasing viscosity of the aqueous phase as well as absorption at interface of the phases and formation of coats around dispersed particles, depending on electrostatic repulsions to stabilize the emulsion. Many factors affect the emulsion activity of pectin, low MW is one of the most important factors, which is itself influenced by the extraction conditions such as extraction temperature and time (16). Emulsifier activity and emulsion stability of the emulsion prepared from the optimum sample of extracted pectin-oil solution $(0.5 \% \mathrm{w} / \mathrm{w})$ are shown in Table 4.

Table 4. Emulsifier activity and stability of oil emulsion / $0.5 \%$ volumetric solution percentage / weight solution of optimum walnut green husk pectin sample

\begin{tabular}{|c|c|c|c|c|c|}
\hline \multirow{3}{*}{$\begin{array}{l}\text { Temperature (celsius degree) } \\
\text { Shelf life time (day) }\end{array}$} & \multirow{3}{*}{$\begin{array}{c}\text { Emulsifier activity percentage } \\
23\end{array}$} & \multicolumn{4}{|c|}{ Emulsion stability percentage } \\
\hline & & \multicolumn{2}{|c|}{4} & \multicolumn{2}{|c|}{23} \\
\hline & & 1 & 30 & 1 & 30 \\
\hline $\begin{array}{l}\text { Optimum sample of walnut green } \\
\text { husk pectin }\end{array}$ & 52.3 & 84.2 & 83.1 & 81.5 & 80.4 \\
\hline
\end{tabular}


The emulsion stability rate did not change one day after sample storage at cold and ambient temperatures and after 30 days of storage.

\section{Fourier transform infrared spectroscopy properties}

Fourier transform infrared spectroscopy has been suggested as a useful technique for the assessment of pectin uric acids. In this study, infrared spectra were used to identify the main pectin functional groups extracted from the optimal sample. The infrared spectrum absorbed by the sample is shown in Figure 6. Table 5 shows the most important peaks introduced for the functional groups (wavelengths and intensities of the functional groups) of the commercial pectin (19) and the optimal pectin sample extracted from walnut husks.

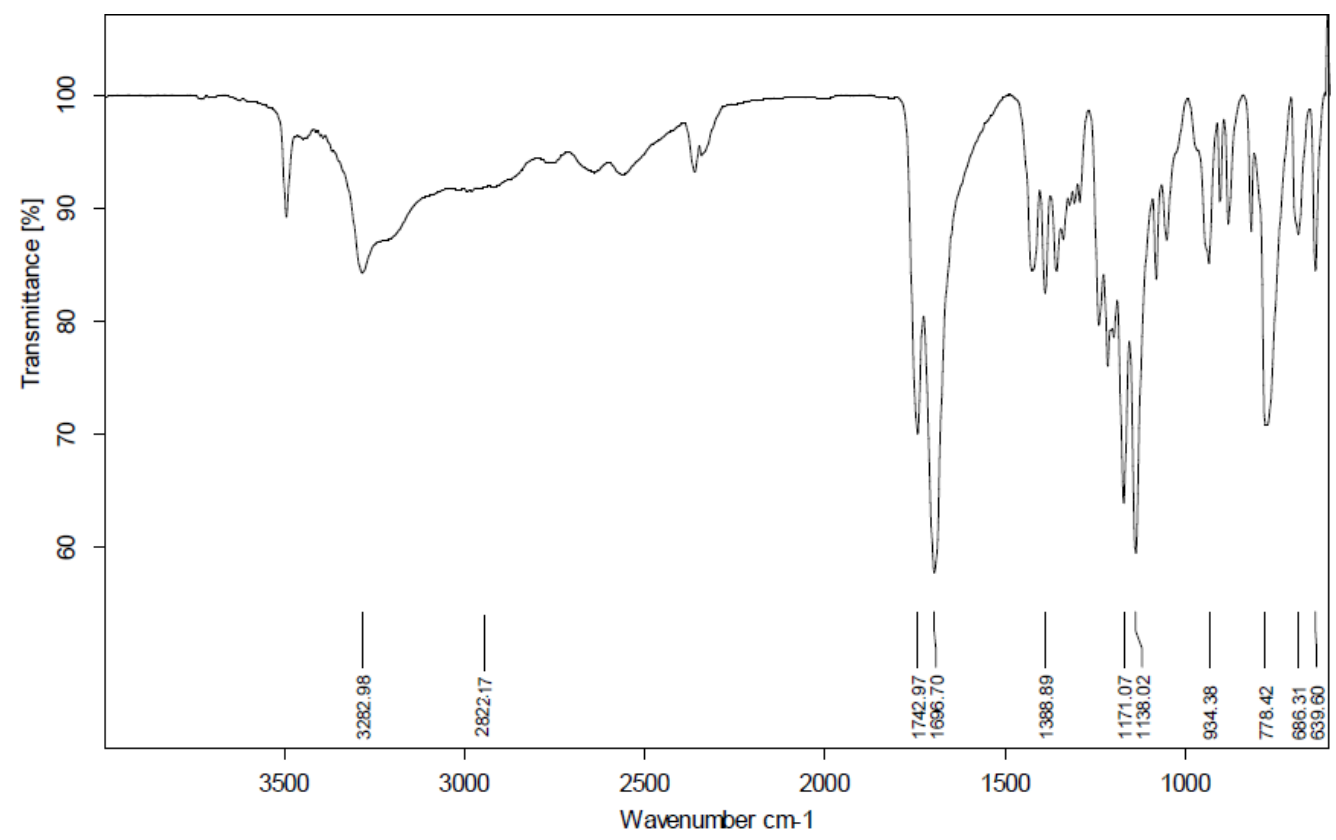

Figure 6. FTIR absorption spectrum of the optimal pectin sample isolated from walnut green husk

Table 5. FTIR absorption spectrum, wavelengths and intensities of commercial pectin functional groups and the optimal sample desired

\begin{tabular}{llcc}
\hline \multirow{2}{*}{ Power } & Functional groups & \multicolumn{1}{c}{$\left(\mathrm{cm}^{-1}\right)$} \\
\hline Broad, strong & Tensile O- H & $\begin{array}{c}\text { Optimum sample of } \\
\text { walnut green husk pectin }\end{array}$ & $\begin{array}{c}\text { Commercial } \\
\text { pectin }\end{array}$ \\
Sharp, occasionally overlap with O - H & Tensile, symmetrical and asymmetrical C- H & 3282 & 3389 \\
Strong & Esterified C=O & 2822 & 2940 \\
Strong and weak & Asymmetrical tensile C=O & 1742 & 1753 \\
Weak & Finger print & 1388 and 1695 & 1441 and 1630 \\
\hline
\end{tabular}

Based on the Five-Peaks Table, $1 \mathrm{~cm}$ range for the optimal pectin sample was linked to the adsorption of 
tensile hydroxyl groups caused by intermolecular hydrogen bonds and various carbon groups $\left(\mathrm{CH}_{1}\right.$, $\mathrm{CH}_{2}, \mathrm{CH}_{3}$ ) at wavelengths of 2822-3282. Region between the bands $1640-1800$ is a special region because it provides structural information and can be used to compare various types of pectins in the optimal pectin sample. Target range of this peak region at 1742 and $1692 \mathrm{~cm}^{-1}$ wavelengths have shown that these adsorptions can be linked to the vibration of tensile carboxyl groups $(\mathrm{C}=\mathrm{O})$ methyl ester and non-esterified carboxyl groups (29). Absorption peaks at the wavelengths of 1388 and 1695 in the optimal pectin sample was linked to the free carboxyl groups (19). Absorption peaks at wavelengths of $1000-1200 \mathrm{~cm}^{-1}$ in both samples can be attributed to the presence of various sugar compounds such as furanose and pyranose in pectin structure.

\section{Discussion}

In general, pectin accumulation may occur with increasing $\mathrm{pH}$ from 1.5 to 2 , which slows its release from the plant cell wall, resulting in reduced pectin efficiency rate (Figure 1a). Low pH decreases MW of the pectin attached to the cell wall of the plant and force it to dissolve and separate from the plant matrix without molecular chain degradation. This results in deposit of the pectin molecules. Furthermore, high acidic strength hydrolyzes insoluble pectin and converts it into soluble pectin that increases the precipitation of pectin, enhancing pectin recovery (19). Although high acidic strength enhances pectin efficiency, but too low $\mathrm{pH}$ can result in formation of very small pectin particles. This changes pectin solubility to a point that cannot be precipitated by the addition of alcohol. Increases in process time and temperature affected the extracted pectin efficiency (Figure 1b). As the extraction time increased, the extraction efficiency rate increased. This was seen because by increasing the extraction time, the insoluble pectin density became solubilized and extraction efficiency rate increased. Researchers have reported temperature as one of the most important factors in extraction of polysaccharides such as pectin (18). As temperature increases, efficiency of the pectin extraction increases; hence, the most efficient pectin extraction was achieved at $80{ }^{\circ} \mathrm{C}$ in the current study. High temperature increased the solubility of the extracted pectin. As a result, pectin extraction rate, diffusion coefficient and extraction rate increased.
Increased temperature also increased solubility of insoluble polysaccharides in alcohol and increased the efficiency rate. Use of temperatures above $95{ }^{\circ} \mathrm{C}$ in pectin extraction processes is not recommended due to increased solubility and mass transfer (18). It can be concluded that the rate of pectin extraction increased with simultaneous increases in temperature and time. As the model equation has shown, the lowest pectin extraction efficiency was achieved at the lowest extraction temperature and time, similar to that reported by other studies (22). As pH increased, this factor increased; therefore, the optimal conditions for pectin extraction efficiency and its esterification degree are different; possibly due to the breakdown of pectin ester bonds in acidic conditions (Figure 2). It is suggested that higher esterification degrees demonstrate less damaged pectins because ester bonds are less resistant to acid hydrolysis than galacturonic acids between alpha 1 and alpha 4 glycosidic bonds. This finding is similar to findings by other researchers, including Nateghi and Ansari (2018). They reported that with increasing $\mathrm{pH}$, efficiency rate and esterification degree respectively decreased and increased (30). Based on the model from the pectin esterification degrees of both compounds, temperature included the second power in the equation and hence the effective factor was identified. The most important result includes the esterification degree of pectin type, which is industrially used for the preparation of ordinary jams of pectin with a esterification degree above $70 \%$ (rapid) or less than $68 \%$ (slow) in highly acidic fruit jams and jellies. In the present study, pectin included low or slow esterification types used to remove heavy metals from the body and decrease activity of the cancer cells (31). Results of pectins from orange peel, carrot pulp, walnut green husk, melon peel, sunflower and eggplant cap in slow pectin group are similar to the results of those from this study and other samples, including pumpkin pectin and eggplant peel in rapid pectin group.

Decreases in galacturonic acid proportion possibly occur because basic hydrolysis of the pectin neutral sugars occurs at $\mathrm{pH}$ above 2 and high temperatures (Figure 3). Previous studies have reported $\mathrm{pH}$ as the most important factor in galacturonic acid proportion, similar to reports from the present study (18). Suggestions have been made about the effects of $\mathrm{pH}$ on pectin purity. One suggestion describes that at $\mathrm{pH}$ 
below 1.5, pectin is extracted because non-pectic compounds dissolve the cell wall and precipitate with alcohol. At the lowest $\mathrm{pH}$, extracted pectin is decomposed into low molecular weight (LMW) compounds and does not precipitate with ethanol (22). However time did not affect the quantity of pectin, the two other factors, temperature and $\mathrm{pH}$, and their interactions included greater effects on this factor. Comparison of results from the esterification degree and galacturonic acid proportion showed that the esterification degree was further sensitive to extraction conditions and the rate of variation was higher, similar to results reported by Fathi et al. (2012), These possibly occurred due to the higher resistance of glycosidic bonds of galacturonic acid to acidic hydrolysis, compared to that of ester bonds. According to the Food and Agriculture Organization of the United Nations (FAO) and the European Union (EU), galacturonic acid proportion in pectin demonstrates pectin purity which must be at least $65 \%$ (18). In the current study, galacturonic acid proportion was reported in a similar range. Results of the ash assessment showed that the ash content of the pectin powder was $1.05 \%$, which is similar to those from previous studies. In the present study, ash content of the sunflower pectin sample was reported as $1.5 \%$ (26). However, results of the ash content assessment in this study were less than the maximum allowed content and the extracted compounds were introduced as edible pectin. The MW of the extracted pectin sample at optimum conditions was $38.88 \mathrm{kDa}$. The MWs of the pectin extracted from pistachio husks and melon peels were 12.87 and $67.6 \mathrm{kDa}$, respectively $(20,27)$. The MW of various sources can be strongly affected by the types of plants and extraction conditions during the process. Low intrinsic viscosity of the pectin could be due to the presence of strongly bonded hemoglacturonic regions, whereas other types of high intrinsic viscosity pectins seem to include regions of helical structures (7).

Dynamic rheological tests in the linear viscoelastic range can include (elastic) storage coefficient $\mathrm{G}^{\prime}$, modulus of dissipation (viscose) $\left(\mathrm{G}^{\prime \prime}\right)$ and dissipation factor $\tan \delta\left(G^{\prime} / G^{\prime}\right)$. Value of the storage coefficient is an indicator of the energy stored in the sample during the shear process and describes the elastic behavior of the sample. The dissipation coefficient is an indicator of the energy consumed in the sample during shearing and the energy wasted in the sample, explaining viscous behavior of the sample (28). If the elastic coefficient $\left(G^{\prime}\right)$ is greater than the viscosity coefficient $\left(\mathrm{G}^{\prime \prime}\right)$, compound behaves like a solid which means that deformation of the material is essentially elastic or recyclable and if the viscosity coefficient (G") is greater than the elastic coefficient $\left(G^{\prime}\right)$. The energy used to change the material form is wasted and the material will behave like a liquid (Figure 5). Moreover, results showed that the elastic coefficient $\left(G^{\prime}\right)$ and storage coefficient $\left(G^{\prime \prime}\right)$ increased with increasing frequency, similar to pectin rheology results of the pistachio husks (25). In Table 4, emulsifier activity of the pectin sample extracted from walnut green husks at $0.5 \%$ concentration and assessed immediately after the test at $23{ }^{\circ} \mathrm{C}$ was $52.3 \%$. This was extracted from the pectin emulsifier activity of sugar beet pulps by citric acid, which was $32.2 \%$ higher and lower than the pectin emulsifier activity of carrot pulps (19). Emulsion stability decreased a little and results showed that the low storage temperature included further emulsifying properties, similar to results from other studies (18, 22). Citrus pectin emulsifier activity at $0.5 \%$ concentration was reported as $49.6 \%$ (32). Pectin from walnut green husks could exhibit a similar activity to citrus pectin under similar conditions. The emulsifier activity and relatively good stability of the resulting pectin can be attributed to the presence of polyphenols (e.g. caffeic acid), as the predominant phenolic acids, as well as hydroxycinnamic chlorogenic acid, as the major acid in tissues. The FTIR results demonstrated appropriate purity of the extracted pectin, as previously demonstrated by other studies (Figure 6) $(22,27,33)$.

\section{Conclusion}

The present study has shown that the highest efficiency rate of walnut green husks $(25.84 \%)$ occurs at optimal conditions of $\mathrm{pH} 1.62$, process temperature of $80{ }^{\circ} \mathrm{C}$ and extraction time of $120 \mathrm{~min}$. Furthermore, the highest esterification degree of pectin from walnut green husks (63.19\%) occurs at optimal conditions of $\mathrm{pH} 2$, process temperature of $72.92{ }^{\circ} \mathrm{C}$ and extraction time of $87.27 \mathrm{~min}$. Esterification degree of the walnut green husk samples includes 52.30-60.20. As galacturonic acid proportion shows purity of pectin, galacturonic acid proportion in these samples was within the standard range. The optimum conditions for achieving the highest proportion of the pectin 
galacturonic acid from walnut green husks $(68.53 \%)$ include $\mathrm{pH} 1.44$, process temperature of $72.92{ }^{\circ} \mathrm{C}$ and extraction time of $93.33 \mathrm{~min}$. The optimum extracted samples include good emulsifier and viscosity properties. In conclusion, walnut green husks are good sources for pectin extraction.

\section{Acknowledgement}

The current manuscript is extracted from a research study (Code 1139606200004) approved by the Islamic Azad University, Roudehen Branch, Roudehen, Iran. The authors would like to express their gratitude to the Vice President for Research and Technology at Islamic Azad University of Roudehen for the financial supports.

\section{Financial disclosure}

The authors declared no financial interest.

\section{References}

1. Yazdankhah S, Hojjati M, Azizi MH. Extraction of phenolic compounds from Black Mulberry using aqueous, ethanol and aqueous-ethanol solvents: effects of heat treatments on chemical properties of the extracts. Nutr Food Sci Res. 2019; 6(3): 39-47.

2. Kakaei K, Noshad M, Nasehi B, Hojjati M, BeiraghiToosi S. Optimization of physicochemical characteristics of corn-based extruded snacks containing pomegranate seed powders. Nutr Food Sci Res. 2019; 6(1): 35-40.

3. Vieira V, Pereira C, Pires TCS, Calhelha RC, Alves MJ, Olga F, Barros L. Phenolic profile, antioxidant and antibacterial properties of Juglans regia $\mathrm{L}$. (walnut) leaves from the Northeast of Portugal. Ind Crops Prod. 2019; 134: 347-355.

4. Anjum S, Gani A, Ahmad M, Shah A, Masoodi FA, Shah Y, Gani A. Antioxidant and antiproliferative activity of walnut extract (Juglans regia L.) processed by different methods and identification of compounds using GC/MS and LC/MS technique. J Food Process Pres. $2017 ; 1(41): 1-9$

5. Krivorotova T, Cirkovas A, Maciulyte S, Staneviciene R, Budriene AS, Serviene E, Sereikaite J. Nisinloaded pectin nanoparticles for food preservation. Food Hydrocoll. 2016; 54:49-56.

6. Didar. Z. Effects of coatings with pectin and cinnamomum verumHydrosolIncluded pectin on physical characteristics and shelf life of chicken eggs stored at $30^{\circ} \mathrm{C}$. Nutr Food Sci Res. 2019; 6(4): 39-45.

7. Yapo, B. M. Pectic substances: from simple pectic polysaccharides to complex pectins, a new hypothetical model. Carbohydr Polym. 2011; 86:373385.
8. Kazemi M, Khodaiyan F, Hosseini S. Eggplant peel as a high potential source of high methylated pectin: Ultrasonic extraction optimization and characterization. LWT. 2019; 105: 182-189

9. Pagán J, Ibarz A, Llorca M, Pagán A, BarbosaCánovas GV. Extraction and characterization of pectin from stored peach pomace. Food Res Int. 2001; 34(7): 605-612.

10. Yapo BM, Robert C, Etienne I, Wathelet B, Paquot M. Effect of extraction conditions on the yield, purity and surface properties of sugar beet pulp pectin extracts. Food Chem. 2007; 100:1356-1364.

11. Iglesias MT, Lozano JE. Extraction and characterization of sunflower pectin. J Food Eng. 2004; 62: 215-223.

12. Emaga T, Ronkart SN, Robert C, Wathelet B, Paquot $M$. Characterisation of pectins extracted from banana peels (Musa AAA) under different conditions using an experimental design. Food Chem. 2008; 108: 463471

13. Liu L, Cao J, Huang J, Cai Y, Yao J. Extraction of pectins with different degrees of esterification from mulberry branch bark. Bioresour Technol. 2010; 101(9): 3268-73.

14. Bagherian H, Zokaee F, Fouladitajar A, Mohtshamy M. Comparisons between conventional, microwaveand ultrasound-assisted methods for extraction of pectin from grapefruit. Chem Eng Process. 2011; 50(11):1237-1243

15. Jiang Y, Du Y, Zhu X, Xiong H, Woo MW, Hu J. Physicochemical and comparative properties of pectins extracted from Akebia trifoliata var. australis peel. Carbohyd polym. 2012; 87: 166- 1669.

16. Fissore EN, Rojas AM, Gerschenson LN, Williams PA. Butternut and beetroot pectins: Characterization and functional properties. Food Hydrocoll. 2013; $31: 172-182$

17. Fuentes RM, Femenia A, Garau MC, MezaVelázquez JA, Simal S, Rosselló C. Ultrasoundassisted extraction of pectins from grape pomace using citric acid: A response surface methodology approach. Carbohyd Polym. 2014; 106:179-189.

18. Hosseini S, Khodaiyan F, Yarmand M. Effect of acid extraction conditions on yield and quality characteristics of pectin from sour orange peel. Iranian Journal of Biosystem Engineering. 2016; 47(2): 231-242. (In Farsi)

19. Jafari F, Khodaiyan F, Kiani H, Hosseini S. Pectin from carrot pomace: Optimization of extraction and physicochemical properties. Carbohyd Polym. 2017; 157:1315-1322.

20. Chaharbaghi E, Khodaiyan F, Hosseini S. Optimization of pectin extraction from pistachio green hull as a new source. Carbohyd Polym. 2017; 171: 112. 
21. Santos JD, Espeleta AF, Branco A, Assis S. Aqueous extraction of pectin from sisal waste. Carbohyd Polym. 2013; 92(2): 1997-2001.

22. Nateghi L, Ansari S, Lavasani SAR. Investigation of yield and physicochemical properties of pectin extracted from eggplant peel. JFST. 2018; 73(14): 13 30 .

23. AOAC. 1995. Official methods of analysis, $\left(15 \mathrm{th}^{\mathrm{ed}}\right)$ edition. Association of Official Analytical Chemists, Washington, DC., USA.

24. Weska RF, Moura JM, Batista LM, Rizzi J, Pinto LAA. Optimization of deacetylation in the production of chitosan from shrimp wastes: use of response surface methodology. J Food Eng. 2007; 80:749-753.

25. Mosayebi V, Emam-Djomeh, Z, Tabatabaei Yazdi, F. Optimization of extraction conditions of pectin by conventional method from black mulberry pomace. JFST. 2017; 62(14): 341-356. (In Farsi)

26. Jannat B, Oveisi MR, Sadeghi N, Behzad M, Behfar A, Hajimahmoodi M, Shohada MR. Determination of Pectin in Sunflower and Its Application in Food Industry. Food Tech Nut. 2016; 13(1): 25-34. (In Farsi)

27. Raji Z, Khodaiyan F, Rezaei K, Kiani H, Hosseini S. Extraction optimization and physicochemical properties of pectin from melon peel. Int $\mathrm{J}$ Biol Macromol. 2017; 98(17):709-716.
28. Rascón-Chu A, Martínez-López AL, Carvajal-Millán E, Ponce de León- Renova NE, Márquez-Escalante J, Romo-Chacón A. Pectin from low quality 'Golden Delicious' apples: composition and gelling capability. Food Chem. 2009; 116:101-103.

29. Gnanasambandam R, Proctor A. Determination of pectin degree of esterification by diffuse reflectance Fourier transforms infrared spectroscopy. Food Chem. $2000 ; 68: 327-332$.

30. Nateghi L, Ansari. Extraction and investigation of physicochemical properties of pectin extracted from eggplant cap waste. JIFT. 2018; 5(2):219-239. (In Farsi)

31. Fathi B, Maghsoudlou Y, Ghorbani M, Khomeiri M. Effect of $\mathrm{pH}$, temperature and time of acidic extraction on the yield and characterization of pectin obtained from pumpkin waste. J food Res. 2012; 22(4): 465-475. (In Farsi)

32. Maa S, Yu S, Zheng J, Wang XL, Bao X, Guo QD. Extraction, characterization and spontaneous emulsifying properties of pectin from sugar beet pulp. Carbohyd Polym. 2013; 98: 750- 753.

33. Grassino AN, Brncic M, Vikic-Topic D, Roca S, Dent M, Brncic SR. Ultrasound assisted extraction and characterization of pectin from tomato waste. Food chem. 2016; 198: 93-100. 